\title{
Article \\ Genetic and Epigenetic Characterization of a Discordant KMT2A/AFF1-Rearranged Infant Monozygotic Twin Pair
}

\author{
Alessia Russo ${ }^{1}{ }^{(}$, Clara Viberti $^{1}$, Katia Mareschi ${ }^{2,3}{ }^{\circledR}$, Elisabetta Casalone ${ }^{1}$, Simonetta Guarrera ${ }^{4,5}{ }^{(0)}$,

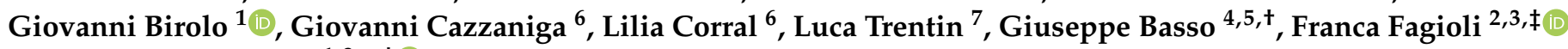 \\ and Giuseppe Matullo ${ }^{1,8, *, \neq(1)}$
}

check for updates

Citation: Russo, A.; Viberti, C.; Mareschi, K.; Casalone, E.; Guarrera, S.; Birolo, G.; Cazzaniga, G.; Corral, L.; Trentin, L.; Basso, G.; et al. Genetic and Epigenetic Characterization of a Discordant KMT2A/AFF1-Rearranged Infant Monozygotic Twin Pair. Int. J. Mol. Sci. 2021, 22, 9740. https:// doi.org/10.3390/ijms22189740

Academic Editor:

Paulina Podszywałow-Bartnicka

Received: 6 August 2021

Accepted: 6 September 2021

Published: 9 September 2021

Publisher's Note: MDPI stays neutral with regard to jurisdictional claims in published maps and institutional affiliations.

Copyright: (c) 2021 by the authors. Licensee MDPI, Basel, Switzerland. This article is an open access article distributed under the terms and conditions of the Creative Commons Attribution (CC BY) license (https:// creativecommons.org/licenses/by/ $4.0 /)$.
1 Department of Medical Sciences, University of Turin, 10126 Turin, Italy; alessia.russo@unito.it (A.R.); clara.viberti@unito.it (C.V.); elisabetta.casalone@unito.it (E.C.); giovanni.birolo@unito.it (G.B.)

2 Stem Cell Transplantation and Cellular Therapy Laboratory, Paediatric Onco-Haematology, City of Health and Science of Turin, Regina Margherita Children's Hospital, 10126 Turin, Italy; katia.mareschi@unito.it (K.M.); franca.fagioli@unito.it (F.F.)

3 Department of Public Health and Paediatrics, University of Turin, 10126 Turin, Italy

4 IIGM-Italian Institute for Genomic Medicine, c/o IRCCS, 10060 Candiolo, Italy; simonetta.guarrera@iigm.it Candiolo Cancer Institute, FPO-IRCCS, 10060 Candiolo, Italy

6 M.Tettamanti Research Center, Pediatric Clinic University of Milano-Bicocca, 20900 Monza, Italy; gianni.cazzaniga@asst-monza.it (G.C.); liliacorralabascal@gmail.com (L.C.)

7 Onco-Hematology Division, Department of Salute Della Donna e Del Bambino (SDB), University of Padua, 35128 Padua, Italy; luca.trentin78@gmail.com

8 Medical Genetics Unit, AOU Città Della Salute e Della Scienza, 10126 Turin, Italy

* Correspondence: giuseppe.matullo@unito.it; Tel.: +39-011-6705601

+ Deceased.

$\ddagger$ These authors contributed equally to this work.

Abstract: The KMT2A/AFF1 rearrangement is associated with an unfavorable prognosis in infant acute lymphocytic leukemia (ALL). Discordant ALL in monozygotic twins is uncommon and represents an attractive resource to evaluate intrauterine environment-genetic interplay in ALL. Mutational and epigenetic profiles were characterized for a discordant KMT2A/AFF1-rearranged infant monozygotic twin pair and their parents, and they were compared to three independent KMT2A/AFF1positive ALL infants, in which the DNA methylation and gene expression profiles were investigated. A de novo Q61H NRAS mutation was detected in the affected twin at diagnosis and backtracked in both twins at birth. The KMT2A/AFF1 rearrangement was absent at birth in both twins. Genetic analyses conducted at birth gave more insights into the timing of the mutation hit. We identified correlations between DNA methylation and gene expression changes for 32 genes in the three independent affected versus remitted patients. The strongest correlations were observed for the $R A B 32$, PDK4, CXCL3, RANBP17, and MACROD2 genes. This epigenetic signature could be a putative target for the development of novel epigenetic-based therapies and could help in explaining the molecular mechanisms characterizing ALL infants with KMT2A/AFF1 fusions.

Keywords: acute lymphoblastic leukemia; exome; DNA methylation; RNA sequencing; NRAS

\section{Introduction}

Acute lymphoblastic leukemia (ALL) represents $25 \%$ of all diagnosed tumors among 0-14-year-old patients [1]. Leukemia in children less than one year old (infants) represents about 3\% of all pediatric ALL and most frequently develops a B-cell ALL form, which is characterized by an uncontrolled proliferation of immature B-cell precursors in the peripheral blood (PB) and bone marrow [2].

The triggering genetic alteration underlying leukemogenesis is a chromosomal translocation occurring at the KMT2A (formerly MLL) gene locus (11q23), with the KMT2A/AFF1 fusion being the most frequent cytogenetic abnormality in infant B-cell ALL. For children in 
the first year of life carrying this translocation, leukemia can arise as an aggressive disease with an unfavorable prognosis. It is still under debate whether KMT2A fusions alone are sufficient to cause clinically overt leukemia [2].

The KMT2A gene encodes a DNA-binding protein that methylates histone $\mathrm{H} 3$ and positively regulates expression of the target genes. A rigorous regulation of DNA methylation and histone modifications are essential for proper hematopoietic cell development. Genome-wide DNA methylation alterations have been described in several studies as able to distinguish ALL samples recruited at diagnosis from matched remission samples and to discriminate B-ALL from T-ALL, as well as B-ALL subtypes. In particular, infants with KMT2A rearrangements exhibit characteristic DNA methylation patterns, depending on the translocation partner, although they all display DNA hypermethylation when compared with normal samples [3]. Considering the even more established role of epigenetics in leukemia subtype classification, prognosis, and progression, DNA methylation signatures have also been suggested as a complementary method for ALL diagnosis in undefined ALL patient groups [4].

Monozygotic twins discordant for leukemia represent a precious opportunity to evaluate the interplay between the intrauterine environment and genetic factors, as they are matched for genotype, age, gender, paternal age, and exposure to several common environmental factors [5]. In those children who share genetic identities and the prenatal environment, the concordance rate of ALL occurring during the first months of life usually reaches $100 \%$ [6]. In the present study, we characterized for the first time the mutational and DNA methylation profiles of a case of monozygotic twins discordant for an infant B-ALL with the KMT2A/AFF1 translocation.

\section{Results}

\subsection{KMT2A/AFF1 Discordancy among Monozygotic Twin Samples}

At the age of 5 months, the twin S1 (Figure 1A) was diagnosed as having pro-BALL, with $\mathrm{t}(4 ; 11)$ involving KMT2A intron 12 (chromosome 11q23) and AFF1 intron 5 (chromosome 4q23) (Supplementary Figure S1). Twin S1 had the clonal IGH VH6-JH3 rearrangement, and no chromosomal translocation involving the KMT2A and AFF1 genes was revealed in the healthy twin sister (S2). Of note, no amplification signal for either KMT2A/AFF1 or IGH VH6-JH3 was detected at birth in the siblings (affected twin: 0/30,000 cells with KMT2A/AFF1 and 0/18,000 cells with IGH VH6-JH3; Healthy twin: 0/39,000 cells with KMT2A/AFF1 and 0/9000 cells with IGH VH6-JH3).

\subsection{Exome Sequencing on Monozygotic Twins Discordant for ALL}

To identify ALL-linked de novo somatic mutations, the siblings and parents were subjected to WES. No high-confidence de novo somatic indel changes were detected in the proband. Among the de novo somatic variants of the proband with global allele frequencies lower than $1 \%$, we detected the missense heterozygous mutation NRAS c.183A > T p.Q61H (variant allele frequency $=26.7 \%$ ) as being absent in all the healthy samples and confirmed this using Sanger sequencing (Supplementary Table S1) (Figure 1B).

In order to determine whether the NRAS mutation was already present at birth or acquired afterward, neonatal blood spots of the twins were scrutinized to search for NRAS p.Q61H mutation by ddPCR, and 0.13 copies $/ \mu \mathrm{L}$ and 0.17 copies $/ \mu \mathrm{L}$ of a mutant allele were detected in both the proband and the healthy twin sister, respectively. 
A.

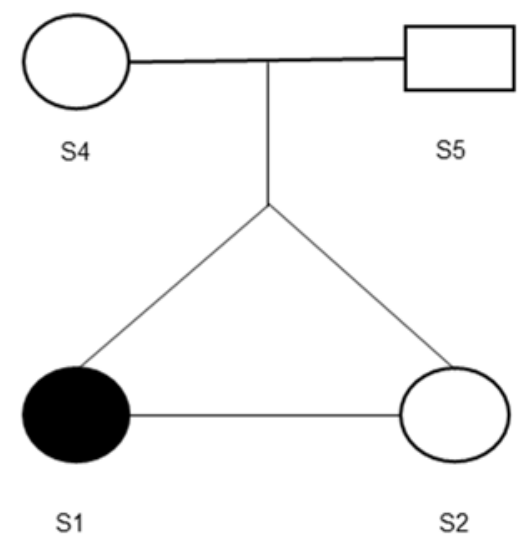

B.

KMT2A-AFF1+

NRASc.183A>T p.Q61 $\mathrm{H}^{+}$

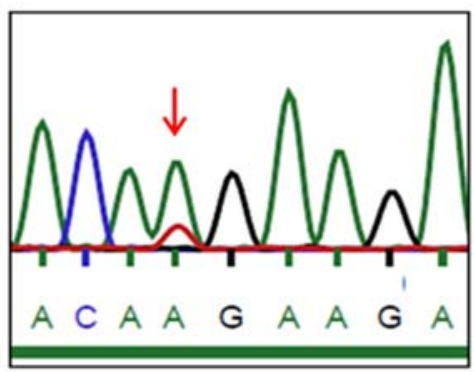

Sanger sequencing validation of NRAS mutation ( $\mathrm{A}>\mathrm{T}$, red arrow)

Figure 1. (A) Twins' family tree. (B) Genetic alterations in the proband at diagnosis.

\subsection{Differential DNA Methylation and Gene Expression}

In all five family samples (S1-S5), a panel of 393,797 CpG was obtained.

In order to specifically identify ALL-related DNA methylation changes in the affected child (S1), we focused our analysis on $8120 \mathrm{CpGs}$, satisfying the following criteria: $\Delta \beta$ values of at least $30 \%$ between the proband (S1) and both her healthy sister (S2) and the remitted sample (S3) and $\Delta \beta$-values $\leq 10 \%$ among the healthy samples (S2 and S3). Most of the CpGs (6599) were consistently hypermethylated in the proband at diagnosis compared with the healthy samples ( $\Delta \beta$-values between $30 \%$ and $82 \%$ ). Among the $8120 \mathrm{CpG}$ sites identified within the twin samples, 5139 were also differentially methylated with similar effects (i.e., $t$-test mean differences of at least $30 \%$ ) and the same directions among the three diagnosis-remission-matched samples (couples $A 1_{d}-A 1_{r}, A 2_{d}-A 2_{r}$, and $A 3_{d}-A 3_{r}$ ) which were derived from three independent (and unrelated) B-ALL infants carrying the KMT2A/AFF1 chromosomal rearrangement (Supplementary Table S2). The majority of these CpGs (4396) were hypermethylated at diagnosis (30-85\% difference) in accordance with what was observed within the twin samples.

In total, the 5139 differentially methylated CpG sites were annotated to 1904 gene regions. The top 20 GSEA results are listed in Supplementary Table S3.

All samples collected at diagnosis $\left(\mathrm{S} 1, \mathrm{~A} 1_{\mathrm{d}}, \mathrm{A} 2_{\mathrm{d}}\right.$, and $\left.\mathrm{A} 3_{\mathrm{d}}\right)$ consisted predominantly of immature B-cells, whereas the remission samples $\left(\mathrm{S} 3, \mathrm{~A} 1_{\mathrm{r}}, \mathrm{A} 2_{\mathrm{r}}\right.$, and $\mathrm{A} 3_{\mathrm{r}}$ ) included a mixture of different mature blood cell populations. To take this difference into account, we subjected the entire methylation dataset shared by the twins (S1, S2, and S3), the three diagnosis-remission-paired samples (couples $A 1_{d}-A 1_{r}, A 2_{d}-A 2_{r}$, and $A 3_{d}-A 3_{r}$ ) and the $\mathrm{CD}^{+} 4^{+}$hematopoietic stem cells $(398,224 \mathrm{CpG}$ sites) to unsupervised clustering analysis. As shown in Figure 2, the first separation clearly divided the affected samples from the healthy samples. 


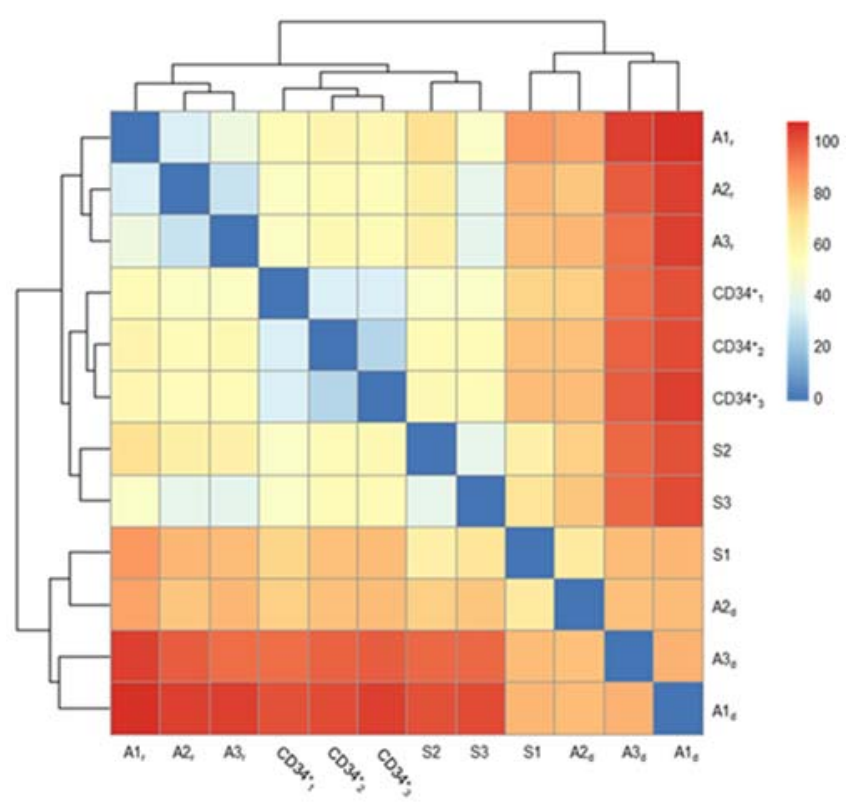

Figure 2. Unsupervised cluster heatmap of the Euclidean distances (0-100) among the twin samples (S1, S2, and S3), the three diagnosis-remission-paired samples (couples $\mathrm{Ai}_{\mathrm{d}}-\mathrm{Ai}_{\mathrm{r}}, \mathrm{i}=1,2,3$ ), and the $\mathrm{CD}_{3}{ }_{\mathrm{i}}{ }^{+}(\mathrm{i}=1,2,3)$ cells based on their DNA methylation values for 398,224 CpG loci.

To verify that the "top" 5139 differentially methylated CpG sites corresponded to a signature characteristic of B-ALL, independent from the different proportion of blood cells in the samples, we compared the $\mathrm{CpG}$ site methylation levels among the leukemic samples $\left(\mathrm{S} 1, \mathrm{~A} 1_{\mathrm{d}}, \mathrm{A} 2_{\mathrm{d}}\right.$, and $\left.\mathrm{A} 3_{\mathrm{d}}\right)$ and non-leukemic samples $\left(\mathrm{S} 2, \mathrm{~S} 3, \mathrm{~A} 1_{\mathrm{r}}, \mathrm{A} 2_{\mathrm{r}}\right.$, and $\left.\mathrm{A} \mathrm{3}_{\mathrm{r}}\right)$ and the non-leukemic $\mathrm{CD} 19^{+} \mathrm{B}$ cells and $\mathrm{CD} 34^{+}$cells isolated from the adult donors and cord blood samples, respectively. This set of non-leukemic reference cells represented mature B-cells $\left(\mathrm{CD} 19^{+}\right)$and multipotent progenitor cells $\left(\mathrm{CD} 34^{+}\right)$. The "targeted" PCA (Figure 3 ) revealed a cluster of B-ALL-affected individuals distinct from the non-leukemic individuals and reference samples. PC2 separated the $\mathrm{CD} 19^{+}$cells from all the other samples. We imputed this result to the different ages between the $\mathrm{CD} 19^{+}$cell donors (adults) versus the infant samples.

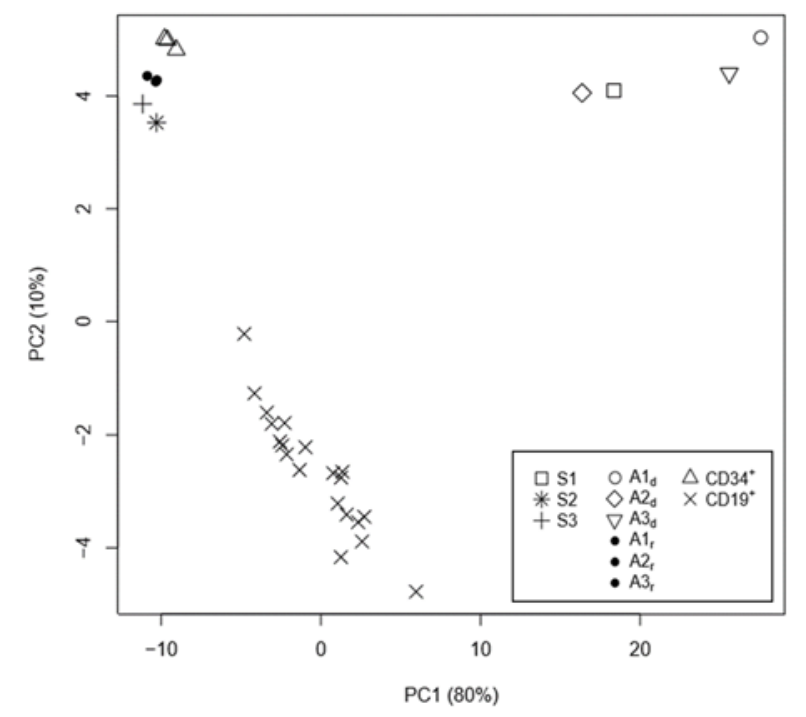

Figure 3. Principal component analysis (PCA) of the DNA methylation values for the "top" 5139 CpG loci among the twin samples (S1, S2, and S3), the three diagnosis-remission-paired samples (couples $\mathrm{Ai}_{\mathrm{d}}-\mathrm{Ai}_{\mathrm{r}}, \mathrm{i}=1,2,3$ ), and the $\mathrm{CD} 34^{+}$and $\mathrm{CD} 19^{+}$cells. 
Whole transcriptome profiles were determined for the four diagnosis-remission samples through mRNA sequencing. Unsupervised hierarchical clustering revealed expression profiles distinguishing the diagnosis samples from the remission samples (Supplementary Figure S2). Specifically, we identified 4376 differentially expressed genes in the diagnosis versus remission samples $\left(1.44<\mid\right.$ Log2FoldChange $\left(\right.$ FC) $\mid<12.34 ; 6.03 \times 10^{-42}<$ PFDR < 0.05; Supplementary Table S4). The downregulated (2536) and upregulated (1840) genes at diagnosis included genes involved in the development or functioning of the immune system, response to stimuli, and characterization of the immune cell subtypes. The top 20 significant overlaps computed for both the down- and upregulated genes are provided in Supplementary Table S5A,B.

Among the 4376 genes significantly up- and downregulated at diagnosis, $363(8.3 \%)$ overlapped those harboring the 5139 differentially methylated CpG sites in both of the twin samples and in the three paired diagnosis-remission samples. We correlated the CpG methylation changes and expression levels. Thirty-two out of 363 genes harbored at least 3 CpGs (134 CpG sites in total; Supplementary Table S6), with rho $\geq \mid$ 0.7 | . Notably, in the healthy parents (S4 and S5), the methylation profiles of these $134 \mathrm{CpG}$ sites were comparable to those of an internal control group composed of healthy adult subjects (data not shown), which excluded possible deregulated patterns potentially transmitted from parents to their daughters.

GSEA analysis performed on the 32 genes whose expression levels correlated with the DNA methylation profiles showed significant overrepresentation of genes upregulated in embryonic stem cells from TCEB3 knock-out mice, cell-cell junctions, and cell movements (FDR $q$-value $<9.36 \times 10^{-3}$; Supplementary Table S7). The differentially methylated CpG sites corresponding to these 32 genes were all hypermethylated at diagnosis, and $65 \%$ of them were within the gene promoter. Negative correlations were observed between methylation and gene expression for all CpGs except for those within the MACROD2 gene and one CpG in the PLEKHG5 $3^{\prime}$ UTR. The expression levels of five genes showed the strongest significance between the affected and healthy subjects (PFDR $<10^{-6}$ ) as well as a correlation higher than $80 \%$ with corresponding DNA methylation changes. In particular, the methylation levels of $11 \mathrm{CpG}$ sites located within 1500bp or 200bp upstream of the transcription starting site (TSS) of the RAB32 gene were inversely correlated with their expression levels $\left(\log 2 \mathrm{FC}=-4.42 ; \mathrm{PFDR}=4.08 \times 10^{-8} ;-0.97 \leq\right.$ rho $\leq-0.84 ;$ Pcorr $\leq 0.04$; Figure 4).

An inverse correlation was also observed between the $\beta$-values of three CpGs within the TSS of the PDK4 gene and mRNA levels $\left(\log 2 \mathrm{FC}=-6.07 ;\right.$ PFDR $=1.26 \times 10^{-8}$; $-0.95 \leq$ rho $\leq-0.89$; Pcorr $\leq 0.02$; Figure 5).

Moreover, the CXCL3 and RANBP17 gene expression values negatively correlated with the corresponding CpGs methylation levels (CXCL3: $\log 2 \mathrm{FC}=-6.09 ; \mathrm{PFDR}=1.03 \times 10^{-7} ;-0.95$ $\leq$ rho $\leq-0.85$; Pcorr $\leq 0.04$ (Figure 6) and RANBP17: $\log 2 \mathrm{FC}=-6.01 ; \mathrm{PFDR}=5.38 \times 10^{-8}$; $-0.93 \leq$ rho $\leq-0.91$; Pcorr $\leq 0.02$; Figure 7). 

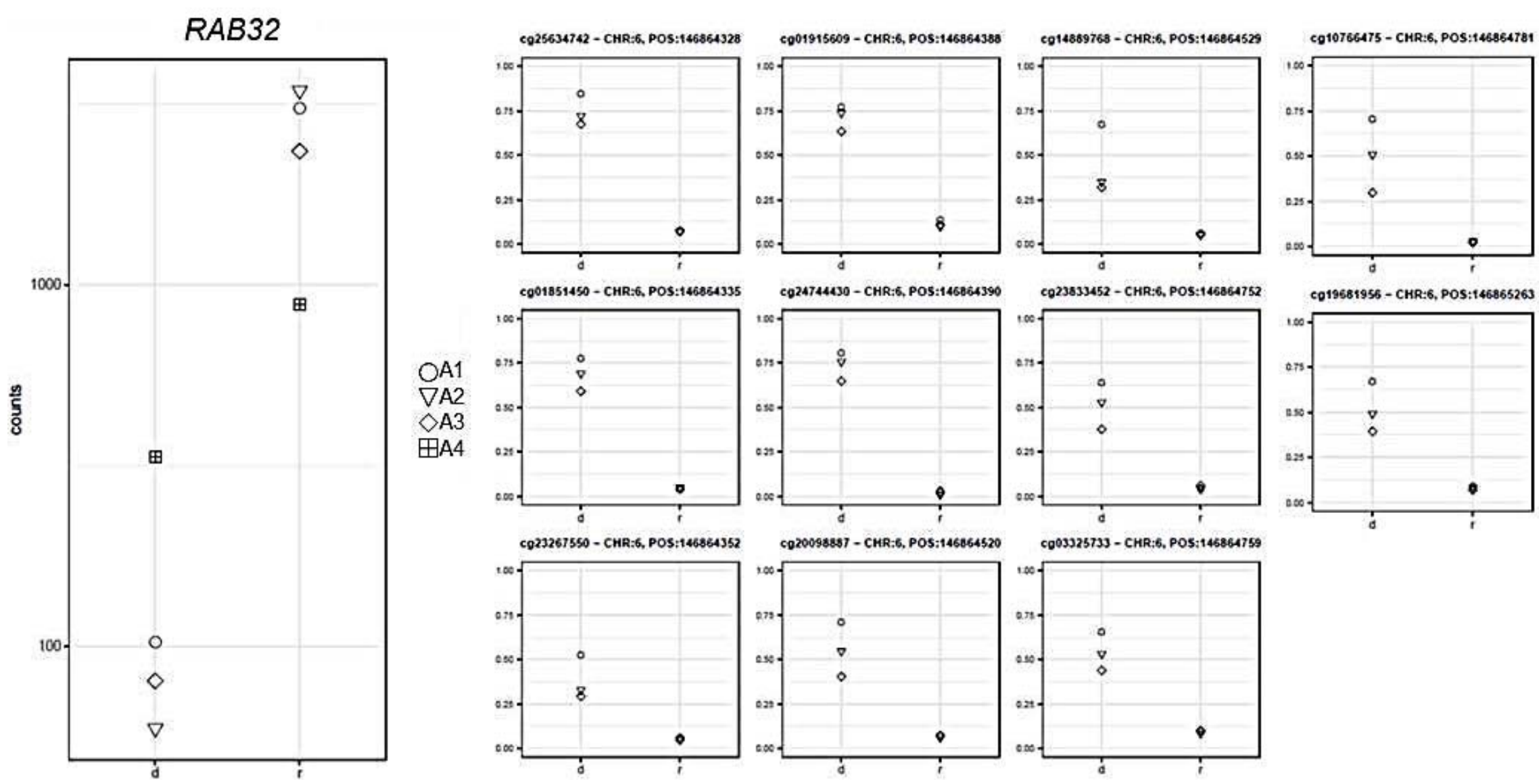

Figure 4. Gene expression (left panel) and corresponding methylation level (y-axis, right panel) comparison between samples at diagnosis (d) and remission (r) for the RAB32 gene. 

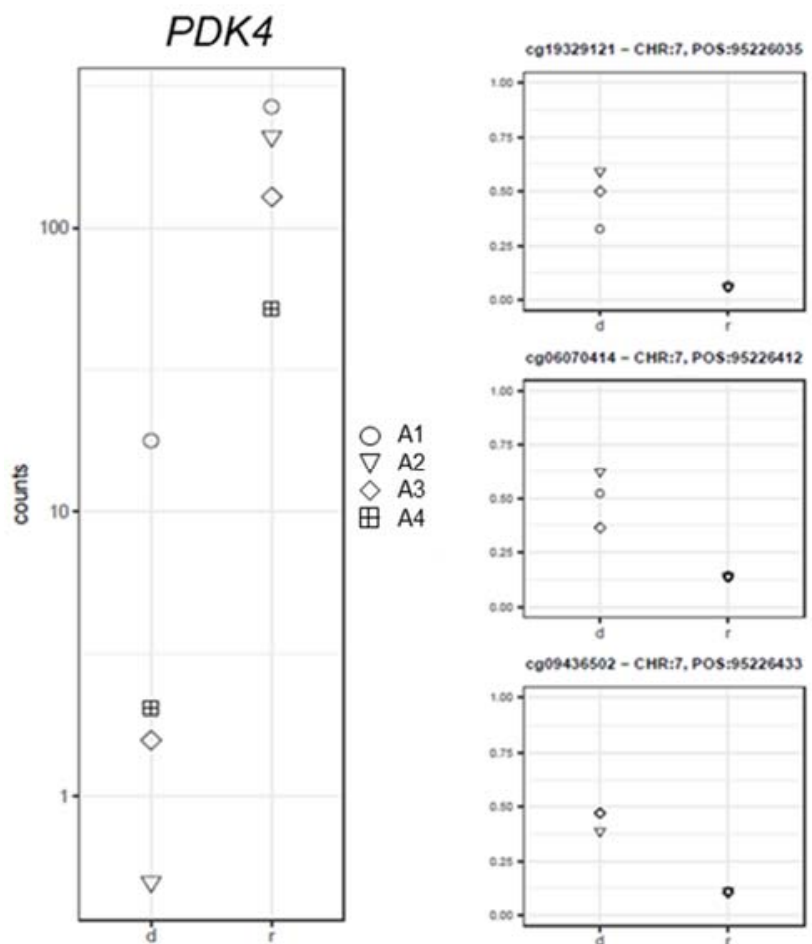

Figure 5. Gene expression (left panel) and corresponding methylation level (right panel) comparison between the samples at diagnosis (d) and remission (r) for the PDK4 gene.
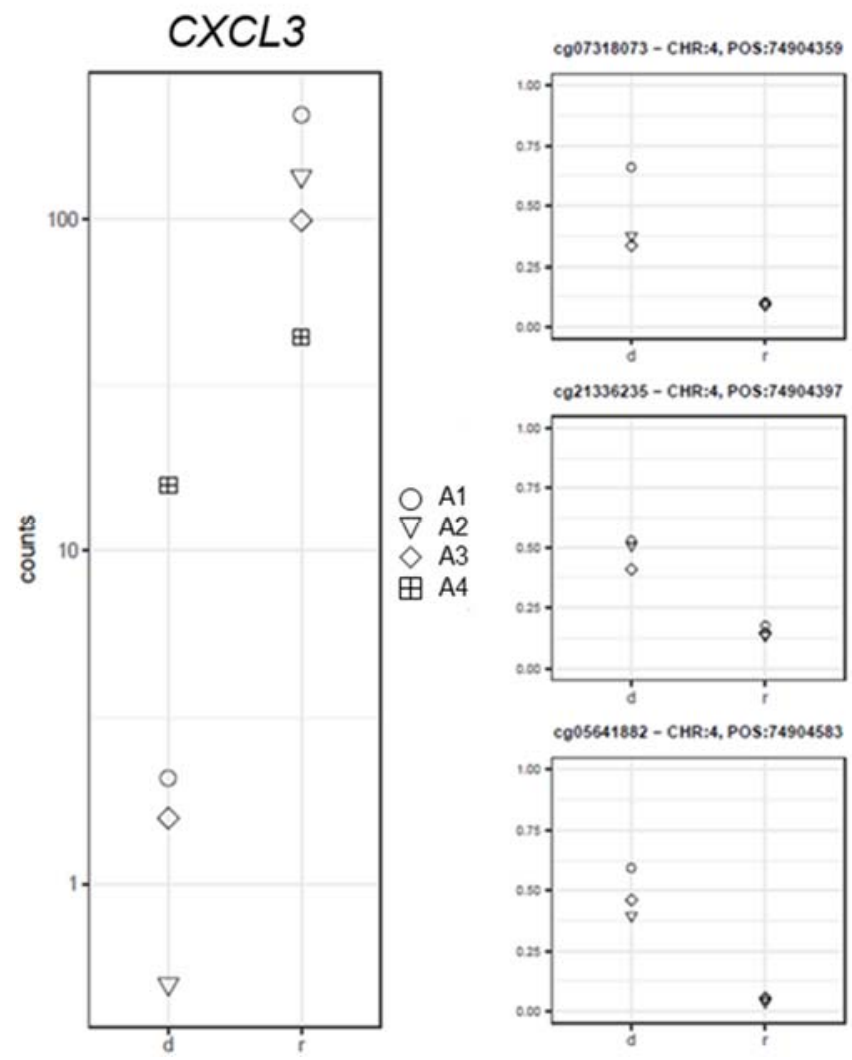

Figure 6. Gene expression (left panel) and corresponding methylation level (right panel) comparison between the samples at diagnosis $(\mathrm{d})$ and remission (r) for the CXCL3 gene. 

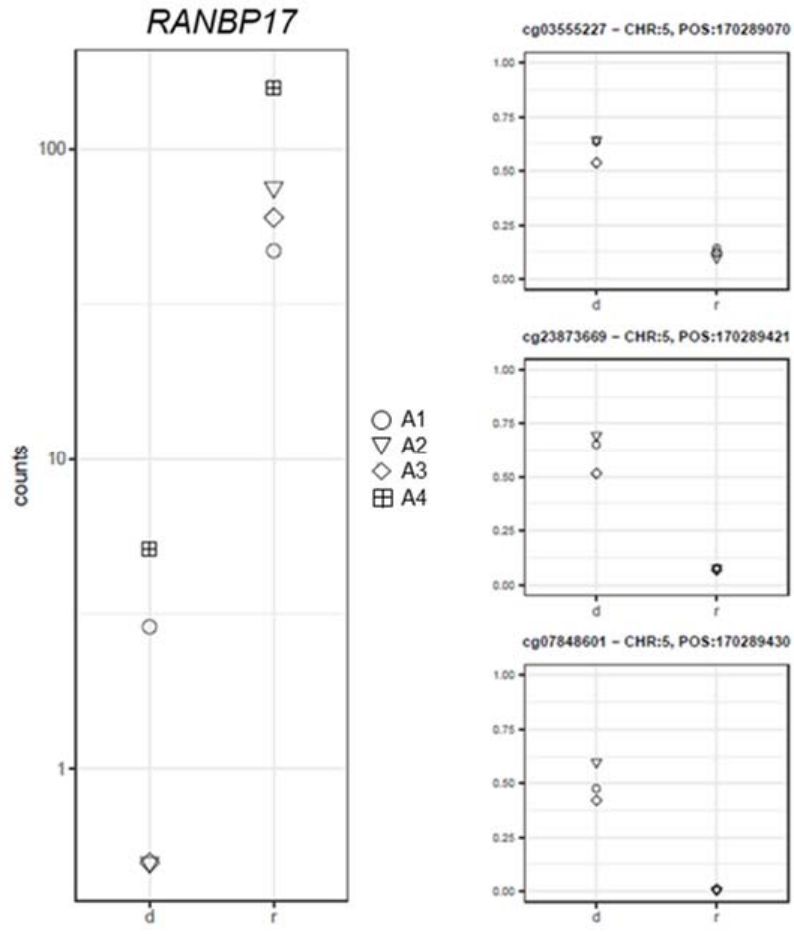

Figure 7. Gene expression (left panel) and corresponding methylation level (right panel) comparison between the samples at diagnosis (d) and remission (r) for the RANBP17 gene.

Conversely, the MACROD2 expression levels decreased at remission and showed a positive association with the methylation levels of nine $\mathrm{CpGs}\left(\log 2 \mathrm{FC}=5.83 ; \mathrm{PFDR}=3.18 \times 10^{-9}\right.$; $0.86 \leq$ rho $\leq$ 0.99; Pcorr $\leq 0.03$; Figure 8).
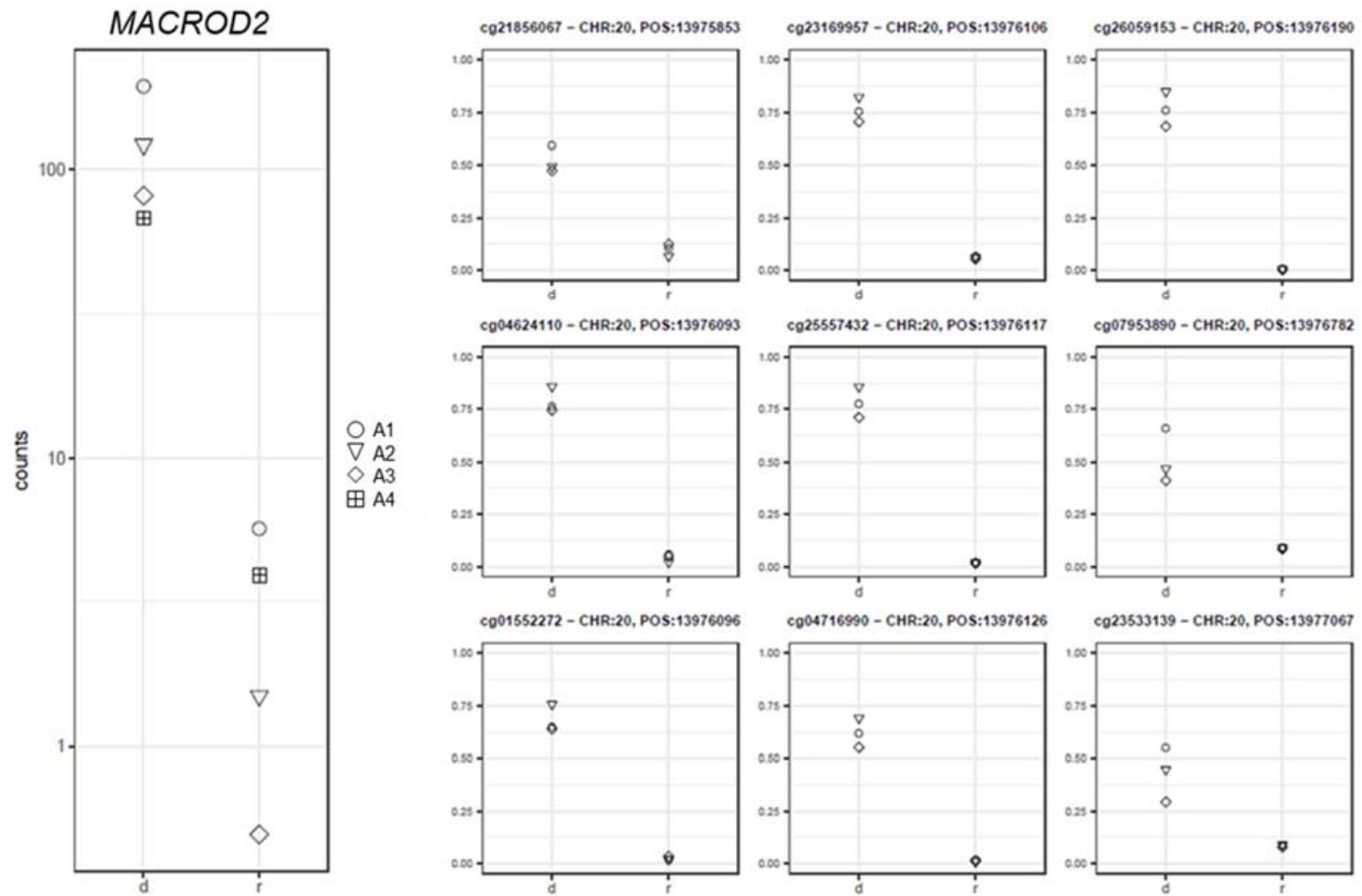

Figure 8. Gene expression (left panel) and corresponding methylation level (right panel) comparison between the samples at diagnosis $(\mathrm{d})$ and remission $(\mathrm{r})$ for the $M A C R O D 2$ gene. 


\section{Discussion}

In the current study, to identify new potential molecular mechanisms characterizing $K M T 2 A / A F F 1^{+}$B-ALL, we investigated, for the first time, the case of monozygotic twins with the discordant diagnosis of KMT2A/AFF1 leukemia by exploiting different "-omics" approaches. Exome sequencing showed only the de novo NRAS Q61H mutation. Wholegenome sequencing has previously revealed a mutational landscape characterized by few non-silent alterations in ALL infants with rearrangements of the KMT2A gene [7,8]. This is consistent with the very short latency period between KMT2A rearrangement onset (often occurring in utero) and the clinically overt leukemia $[9,10]$. The NRAS Q61H mutant allele frequency well below $50 \%$ in the proband confirms the subclonal nature of the mutation [7]. A high frequency of RAS mutations has been reported in infant patients, supporting the hypothesis that RAS activation may be responsible for the shortened latency [11]. Moreover, NRAS mutations seem to contribute to the adverse prognosis typical of KMT2A-rearranged infant patients [12-15].

In our study, the NRAS mutation was also backtracked in the siblings' neonatal blood spots, suggesting that the mutation event arose during the prenatal period. In contrast, no pre-leukemic cells with the KMT2A/AFF1 rearrangement were detected in either twins at birth. These results offer two hypothetical scenarios: (1) a post-natal chromosomal rearrangement event, which would indicate that the NRAS subclonal mutation preceded the chromosomal aberration, a phenomenon recently described in an infant with acute myelomonocytic leukemia [16], or (2) undetectable rearranged blasts could have been present in both the neonatal twins. Considering the fact that most ALL infants could have less than one pre-leukemic blast of over 104 nucleated cells at birth [17], and we did not even observe the patient-specific clonal IGH VH6-JH3 rearrangement, we could not exclude the presence of a silent pre-leukemic clone. We could speculate the existence of a clone with the KMT2A/AFF1 fusion, which competes with the NRAS-mutated clone and initiates the leukemic process, and a minor, which may accelerate the development of the overt leukemia.

The discordancy for leukemia in monozygotic twins is very rare [6,18-20]. Placental anastomoses together with the early onset of the disease support a prenatal origin of leukemia, with a concordance rate among identical twins reaching $100 \%$ [6]. Three hypotheses could explain the discordancy for ALL: (1) The pre-leukemic clones remain in a dormant state in the healthy child, as it was shown that, occasionally, pre-leukemic clones can last up to 14 years [21]. (2) The clearance of the pre-leukemic clones happened within the healthy infant. This speculation is based on the adrenal hypothesis that proposes an anti-leukemic effect as a consequence of cortisol secretion occurring during an early infectious process [22]. (3) The MLL rearrangement was post-natal in the ALL twin only [16].

Aside from genetic alterations, we reported B-ALL-associated DNA hypermethylation in the KMT2A/AFF1-positive twin infant at diagnosis, which reverted after chemotherapy treatment. DNA methylation changes were replicated in three independent diagnosisremission-matched samples carrying the KMT2A/AFF1 rearrangement.

GSEA performed on the diagnosis vs. remission differentially methylated genes highlighted a significant enrichment for target genes of polycomb repressive complex 2 , a histone methyltransferase associated with gene repression which plays a fundamental role in the fine regulation of pluripotent stem cells [23]. Among significantly different expressed genes, crucial leukemogenic genes known to be targets of the KMT2A/AFF1 fusion protein (for example, HOXAs and MEIS1 genes) were upregulated at diagnosis, as expected [24]. We also reported DNA methylation changes that mostly translated into significantly downregulated genes related to TCEB3 expression (Supplementary Table S7). The protein product of TCEB3, Elongin A, forms a stable complex with Elongins B and C, which are required to maintain low expression levels of PCR2-repressed genomic targets $[25,26]$. We observed the strongest correlations between methylation changes and corresponding gene expression for the RAB32, PDK4, RANBP17, CXCL3, and MACROD2 genes. Rab small 
GTPases are a member of the RAS oncogene superfamily [27]. Aberrant DNA methylation of $R A B 32$ was already described in a heterogeneous group of B-ALL pediatric patients harboring different chromosomal rearrangements, including KMT2A/AFF1. However, in comparing leukemic samples with non-leukemic samples, $R A B 32$ gene expression and methylation were not significantly correlated, probably due to the presence of mixed B-ALL subtypes [28]. Higher RAB32 mRNA expression was also described in good-prognosis pediatric patients affected by AML compared with those with poor prognosis [29] and in adult AML patients versus healthy volunteers [30]. Therefore, lower RAB32 gene expression seems to be associated with a malignant phenotype.

PDK4 hypermethylation has been reported for pediatric B-ALL patients with the ETV6-RUNX1 translocation [31]. Bohl and colleagues found an association between PDK4 expression and the lack of a response to the hypomethylating agent decitabine in AML patients. This gene is a poor prognostic marker and has been associated with EVI1and FLT3-ITD-mediated signaling [32]. Disruption of the RanBP17/Hox11L2 region was described in ALL children [33].

The chemokine CXCL3 was found to be epigenetically repressed in B-cell ALL [28]. Consistently, this gene was downregulated in our patients at diagnosis. Chemokine signaling in ALL may have a role in the localization of leukemic blasts in specific niches, and it may confer resistance to chemotherapy [34].

In the samples at diagnosis, MACROD2 expression was considerably higher than in the remission samples. Translocations affecting the MACROD2 gene were reported in a recurrent hyperdiploid ALL pediatric patient at relapse, characterized by several chromothriptic events $[35,36]$. A number of studies suggest a potential role of MACROD2 in cancer; however, it is not clear whether high or low MACROD2 expression levels contribute to tumorigenesis [37]. We reported the lack of an inverse correlation between $M A C R O D 2$ expression levels and the promoter methylation, which may indicate a different mechanism of gene expression regulation, such as histone modifications in the promoter or the involvement of different isoforms. In summary, these five top-ranked genes were reported here for the first time as deregulated genes in KMT2A/AFF1 infants.

Among the other genes with strong correlations between DNA methylation and gene expression (Supplementary Table S6), aberrant DNA methylation and downregulation of FKBP9, CA8, MSC, TRPC6, ZNF492, ZNF229, and ZNF471 genes in leukemia patients are reported here for the first time.

New potential therapeutic targets are necessary, particularly for infants who respond poorly to conventional chemotherapy, and allogeneic hematopoietic stem cell transplantation with an HLA-matched donor is recommended [38]. Given the reversible nature of methylation changes, they represent attractive therapeutic targets. DNA methylation profiling could be important to monitor the efficacy of these novel therapies. Moreover, the accurate assignment of patients to specific risk groups is currently a difficult and expensive process, requiring immunophenotyping, cytogenetics, and molecular diagnostics [39,40]. To conclude, the signature consisting of 32 genes whose methylation levels were reported here to be strongly and significantly correlated with expression changes could be a putative target for the development of novel epigenetic-based therapies and are worthy of further investigations to better understand the molecular mechanisms underlining the dismal prognosis of ALL infants with KMT2A/AFF1 fusions.

\section{Materials and Methods}

\subsection{Cases and Biological Samples}

Monochorionic twin sisters were born by cesarean section at 35 weeks of gestation, conceived after monochorionic in vitro fertilization. At 5 months of age, one child was diagnosed as pro-B ALL positive for the translocation KMT2A/AFF1, with $75 \%$ of blasts at the cytofluorimetric analysis $\left(\mathrm{CD} 10^{-}, \mathrm{CD} 19^{+}\right)$and $80 \%$ of blasts at the morphological analysis. The patient was treated as a high-risk infant ALL according to the INTERFANT-06 protocol (EudraCT Number: 2005-004599-19; ClinicalTrials.gov Identifier: NCT00550992) 
in AIEOP (Associazione Italiana Ematologia Oncologia Pediatrica) centers in Italy. After induction chemotherapy, she achieved complete remission and then received cord blood allogenic hematopoietic stem cell transplantation from an unrelated donor.

Mononuclear cells were collected from the affected child at diagnosis (S1) and at complete remission prior to allogeneic hematopoietic cell transplantation (S3), as well as from her healthy monozygotic twin sister (S2) (Figure 1A). PB was also collected from their healthy parents (S4, S5) (Figure 1A). DNA samples were extracted using a QIAamp DNA Blood Kit (Qiagen, Hilden, Germany).

$\mathrm{PB}$ from the twin sisters was drawn during the first hours post-partum and spotted onto Guthrie cards. Neonatal DNA was extracted using a QIAamp DNA Mini Kit (Qiagen, Hilden, Germany) from a quarter of the Guthrie cards. Details on breakpoint sequencing and searching for rearrangements in the twin sisters at birth and at diagnosis are provided in Appendix A.1.

To perform NRAS mutation analysis in the twin sisters' neonatal spots, DNA was extracted from half of the Guthrie cards using the QIAamp DNA Investigator FTA and Guthrie cards kit (Qiagen, Hilden, Germany). DNA was quantified using the Quant-iT High-Sensitivity dsDNA Assay Kit (Thermo Fisher Scientific, Waltham, MA, USA).

In addition, we recruited four unrelated samples from infant patients with clinical characteristics in line with the twin specimens. The samples (i.e., $A 1_{d}-A 1_{r}, A 2_{d}-A 2_{r}$, $\mathrm{A} 3_{\mathrm{d}}-\mathrm{A} 3_{\mathrm{r}}$, and $\left.\mathrm{A} 4_{\mathrm{d}}-\mathrm{A} 4_{\mathrm{r}}\right)$ were collected at the time of diagnosis $\left({ }_{\mathrm{d}}\right)$ and remission $(\mathrm{r})$; DNA $\left(\mathrm{A} 1_{d}-\mathrm{A} 1_{r}, \mathrm{~A} 2_{d}-\mathrm{A} 2_{r}\right.$, and $\mathrm{A} 3_{d}-\mathrm{A} 3_{r}$ ) or RNA $\left(\mathrm{A} 1_{d}-\mathrm{A} 1_{r}, A 2_{d}-\mathrm{A} 2_{r}, A 3_{d}-A 3_{r}\right.$, and $\left.A 4_{d}-A 4_{r}\right)$ were isolated from the total bone marrow or PB (Supplementary Table S8).

Informed consent was obtained from the parents. The present study was carried out in accordance with the ethical principles of the Declaration of Helsinki.

\subsection{Whole-Exome Sequencing}

Whole-exome sequencing (WES) was conducted on five samples (S1-S5) as detailed in Appendix A.1.

\subsection{Sanger Sequencing}

NRAS exon 3 was subjected to Sanger sequencing at the Eurofins Genomics facilities (Ebersberg, Germany) to confirm the presence of the p.Q61H mutation identified by WES in the proband sample at diagnosis as well as its absence in her healthy twin sister and in their parents.

\subsection{NRAS Mutation Analysis in the Twin Sisters' Neonatal Spots}

The presence of the NRAS c.183A > T p.Q61H mutation was assessed using the QuantStudio 3D Digital PCR instrument and chips (Thermo Fisher Scientific, Waltham, MA, USA). Absolute quantification of the target sequence was obtained through 20,000 simultaneous PCR reactions. Details are provided in Appendix A.1. The results are reported as copies per microliters (copies $/ \mu \mathrm{L}$ ) calculated from the fluorescence signal generated by the amplification of the mutant allele targeted by the FAM dye-labeled probe and the wild-type allele targeted with the VIC dye-labeled probe.

\subsection{DNA Methylation and mRNA Expression Analysis}

Samples $\mathrm{S} 1-\mathrm{S} 5$ and $\mathrm{A} 1_{\mathrm{d}}-\mathrm{A} 1_{\mathrm{r}}, \mathrm{A} 2_{\mathrm{d}}-\mathrm{A} 2_{\mathrm{r}}$, and $\mathrm{A} 3_{\mathrm{d}}-\mathrm{A} 3_{\mathrm{r}}$ underwent DNA methylation analysis using the HumanMethylation450 BeadChip (Illumina, San Diego, CA, USA). The total RNA of four B-ALL patients at diagnosis $\left(\mathrm{A} 1_{d}, A 2_{d}, A 3_{d}\right.$, and $\left.A 4_{d}\right)$ and the same four patients at remission $\left(\mathrm{A} 1_{r}, A 2_{r}, A 3_{r}\right.$, and $\left.A 4_{r}\right)$ were also processed using the TruSeq RNA Sample Prep V2 (Illumina, San Diego, CA, USA) to perform whole-transcriptome analysis. Additional information and statistical analysis are presented in Appendix A.1. 


\subsection{Statistical Analysis}

In order to identify the most differentially methylated CpG sites among the proband, the remitted proband, and the healthy monozygotic sister, a threshold of at least $30 \%$ methylation difference was set (i.e., $\mid \beta$-value proband $-\beta$-value $_{\text {remission }} \mid \geq 0.3$ and $\mid$ $\beta$-value proband $\beta$-value healthy sister $\mid \geq 0.3$ ). Similarly, to ensure that the remaining sites were not differentially methylated between the healthy twin and the remitted proband, a threshold of at most $10 \%$ methylation difference was fixed. We named the $\Delta \beta$-value the difference in the methylation level of the same CpG site between two different individuals. The resulting CpG sites were then intersected with the differentially methylated ones in the three B-ALL diagnosis-remission-matched samples, previously obtained through a paired $t$-test ( $\mid$ effect size $\mid>30 \%$ ).

Principal component analysis (PCA), together with cluster heatmaps, was conducted considering the S1, S2, and S3 samples together with independent B-ALL diagnosisremission-matched samples $\left(A 1_{d}-A 1_{r}, A 2_{d}-A 2_{r}\right.$, and $\left.A 3_{d}-A 3_{r}\right)$ and methylation profiles from $\mathrm{CD} 34^{+}$hematopoietic stem cells isolated from fresh umbilical cord blood derived from three healthy blood donors (GEO Accession Number: GSE40799). CD19 ${ }^{+}$cells from 20 healthy adult blood donors were also used as non-leukemic reference cells (GEO Accession Number: GSE49031).

For multiple comparison tests (Bioconductor package DeSeq2) performed on wholegene expression data generated for four acute leukemia diagnosis-remission couples $\left(\mathrm{A} 1_{d}-\mathrm{A} 1_{r}, \mathrm{~A} 2_{d}-\mathrm{A} 2_{r}, A 3_{d}-\mathrm{A} 3_{r}\right.$, and $\left.\mathrm{A} 4_{d}-\mathrm{A} 4_{r}\right)$, a Benjamini-Hochberg false discovery rate (FDR) $p$-value $\left(\mathrm{P}_{\mathrm{FDR}}\right)$ lower than 0.05 was considered statistically significant.

The "top" CpG sites (i.e., those identified within the twin samples and the three diagnosis-remission-matched samples) were mapped to genes also significantly differentially expressed and underwent subsequent analyses of the Pearson correlation between their methylation level and the expression variation of the corresponding gene. This possible relationship was assessed in the three B-ALL diagnosis-remission couples, because both DNA and RNA were available for them.

All the analyses were performed with the open source R (R 3.1.0) package.

Gene enrichment analysis was performed using the gene set enrichment analysis computational method (GSEA; Broad Institute; http:/ / software.broadinstitute.org/gsea (accessed on 31 December 2019)) to search for a statistically significant set of genes. The annotated gene sets are collected in the Molecular Signatures Database (MSigDB) v6.2 [41]. Enrichments with $p$-values $<0.05$ after correction for multiple comparisons by FDR were considered statistically significant.

Supplementary Materials: The following are available online at https:/ /www.mdpi.com/article/10 .3390/ijms22189740/s1. Figure S1: Breakpoint sequence for KMT2A/AFF1 rearrangement. Figure S2: Unsupervised clustering analysis of the Euclidean distances of gene expression data $(30,864$ genes) in the four diagnosis-remission-paired samples (couples $\mathrm{Ai}_{d}-\mathrm{Ai}_{\mathrm{r}}, \mathrm{i}=1,2,3,4$ ). Table S1: Sample $\mathrm{S} 1$. De novo single-nucleotide variants within gene regions and with a population frequency $<1 \%$. Table S2: CpG sites with at least 30\% methylation differences between the twin samples (S1 and S2) and between three diagnosis-remission-matched samples $\left(A 1_{d}-A 1_{r}, A 2_{d}-A 2_{r}\right.$, and $\left.A 3_{d}-A 3_{r}\right)$. Table S3: Gene set enrichment analysis. The top 20 overlap with the false discovery rate (FDR) ( $q$-value $<0.05)$ computed for 1904 genes. Table S4: Genes with significantly different expression levels in the diagnosis $\left(A 1_{d}, A 2_{d}, A 3_{d}\right.$, and $\left.A 4_{d}\right)$ versus remission $\left(A 1_{r}, A 2_{r}, A 3_{r}\right.$, and $\left.A 4_{r}\right)$ samples. Table S5-A: Gene set enrichment analysis. The top 20 overlap with the FDR ( $q$-value $<0.05)$ computed for the 2536 downregulated genes. Table S5-B: Gene set enrichment analysis. The top 20 overlap with the FDR ( $q$-value < 0.05) computed for the 1840 upregulated genes. Table S6: Correlation between DNA methylation and gene expression levels. Table S7: Gene set enrichment analysis performed on 32 genes with significant correlations between DNA methylation and gene expression. Table S8: Clinical characteristics of the four unrelated leukemia patients. 
Author Contributions: Conceptualization, G.M., F.F. and G.B. (Giuseppe Basso); methodology, A.R., E.C., S.G., L.C., K.M., C.V. and G.B. (Giovanni Birolo); validation, A.R., E.C. and C.V.; formal analysis, A.R. and C.V.; investigation, A.R., E.C., C.V., S.G., K.M., L.T., G.C., G.B. (Giuseppe Basso), F.F. and G.M.; resources, G.M., K.M., L.T., F.F. and G.B. (Giuseppe Basso); data curation, A.R., C.V. and E.C.; writing-original draft preparation, A.R., C.V., E.C. and K.M.; writing-review and editing, A.R., C.V., K.M., E.C., G.B. (Giovanni Birolo), S.G., L.T., L.C., G.C., G.M., G.B. (Giuseppe Basso) and F.F.; visualization, A.R., C.V., E.C., G.B. (Giovanni Birolo), S.G., K.M., L.T., L.C., G.C., G.M., G.B. (Giuseppe Basso) and F.F.; supervision, G.M., F.F. and G.B. (Giuseppe Basso); project administration, A.R. and G.M.; funding acquisition, G.M. All authors have read and agreed to the published version of the manuscript.

Funding: This research was funded by funding specifically dedicated to the Department of Medical Sciences of the Italian Ministry for Education, University and Research (Ministero dell'Istruzione, dell'Università e della Ricerca (MIUR)) under the program "Dipartimenti di Eccellenza 2018-2022", Project no. D15D18000410001. The research leading to these results also received funding from AIRC under IG 2018, ID. 21390 project-P.I. Matullo Giuseppe.

Institutional Review Board Statement: This study was conducted according to the guidelines of the Declaration of Helsinki, and approved by Ospedale Infantile Regina Margherita-Sant'Anna-Ordine Mauriziano hospitals' ethics committees (protocol 37/CEI, 14/6/2007). Infants were treated with Interfant-06 protocols in AIEOP (Associazione Italiana Ematologia Oncologia Pediatrica) centers in Italy.

Informed Consent Statement: Informed consent was obtained from all subjects involved in the study.

Data Availability Statement: Data are contained within the article or Supplementary Materials.

Acknowledgments: We thank Rolf Marschalek (Diagnostic Center of Acute Leukemia (DCAL), Goethe University Frankfurt, Germany) for the KMT2A/AFF1 breakpoint sequencing and Lorenzo Sangiorgio for digital PCR analysis at the Thermo Fisher Scientific Center (Monza, Italy).

Conflicts of Interest: The authors declare no conflict of interest.

\section{Appendix A}

\section{Appendix A.1. Supplementary Methods A1}

Appendix A.1.1. Breakpoint Sequencing, Minimal Disease Monitoring, and Rearrangement Testing

The KMT2A/AFF1 breakpoint was sequenced at the Diagnostic Center of Acute Leukemia (DCAL) at Goethe University Frankfurt, Germany. Based on the genomic breakpoint, a DNA-based quantitative PCR (qPCR) assay was set up to monitor the genomic breakpoint with a sensitivity of $1 \times 10^{-4}$. The clonal immunoglobulin and T-cell receptor somatic gene rearrangements were identified at diagnosis [42] to be used for minimal residual disease monitoring. The qPCR for the IGH VH6-JH3 rearrangement showed a sensitivity of $1 \times 10^{-5}$.

The neonatal DNA quantity was assessed by qPCR amplification of the albumin gene, and the qPCR was used to evaluate the presence of both the KMT2A/AFF1 and the patient-specific clonal IGH VH6-JH3 rearrangement identified at diagnosis. For the affected twin (S1), 10 replicates were performed to test for the KMT2A/AFF1 translocation, and 6 were performed for IGH VH6-JH3. For the twin sister (S2), 13 replicates were carried out for the KMT2A/AFF1 arrangements and 3 for the IGH VH6-JH3 rearrangements. The amount of DNA for each replicate was retrieved from about 3000 cells.

\section{Appendix A.1.2. Whole-Exome Sequencing}

Whole-exome sequencing (WES) was conducted on five samples (S1-S5) using the SureSelect Human All Exon V5+UTRs (74.6 Mb) enrichment panel and the SureSelectQXT protocol (Agilent Technologies, Santa Clara, CA, USA). Exome-enriched libraries were sequenced on the NextSeq500 platform (Illumina, San Diego, CA, USA). The reads were aligned to the human reference genome hg19 using a Burrows-Wheeler aligner (BWA- 
0.7.10) [43]. Variant calling and hard filtering were performed using Genome Analysis ToolKit (GATK)-HaplotypeCaller v3.2-2 and GATK-VariantFiltration v3.2-2 [44]. Visual exploration of the sequencing data was conducted using the Integrated Genomics Viewer tool (IGV; Broad Institute, http:/ / software.broadinstitute.org/software/igv/ (accessed on 31 December 2019)). The variant frequencies were assessed using the 1000 Genomes (http:/ / www.1000genomes.org/ (accessed on 31 December 2019)) and ExAc databases (http:/ / exac.broadinstitute.org/ (accessed on 31 December 2019)). Variant annotation and prioritization were performed using different tools: VariantStudio software (Illumina, San Diego, CA, USA), Alamut (Interactive Biosoftware, Rouen, France), Mutation Assessor (http:/ / mutationassessor.org/ (accessed on 31 December 2019)), Provean (http:/ / provean. jcvi.org/ (accessed on 31 December 2019)), and Mutation Taster (www.mutationtaster.org/ (accessed on 31 December 2019)). Variants causing amino acid changes and with deleterious or damaging predictions in at least three out of five prediction tools were selected.

Appendix A.1.3. NRAS Mutation Analysis in the Twin Sisters' Neonatal Spots

The presence of the NRAS c.183A > T p.Q61H mutation was assessed using the QuantStudio 3D Digital PCR instrument and chips (Thermo Fisher Scientific, Waltham, MA, USA). Absolute quantification of the target sequence was obtained through 20,000 simultaneous PCR reactions.

The purchased primers and probes for the NRAS Q61H mutation analysis were the TaqMan ${ }^{\circledR}$ SNP Genotyping Assay (Thermo Fisher Scientific, assay ID C_166032675_10). The digital PCR mixture $(15 \mu \mathrm{L})$ included $7.5 \mu \mathrm{L} 2 \times$ QuantStudio ${ }^{\circledR}$ 3D Digital PCR Master Mix v2 (Thermo Fisher Scientific, Waltham, MA, USA), $0.75 \mu \mathrm{L}$ TaqMan ${ }^{\circledR}$ SNP Genotyping Assay, $6.75 \mu \mathrm{L}$ DNA (10 ng), and distilled water. Using the QuantStudio 3D Digital PCR Chip Loader, the mixture was loaded on a chip of the QuantStudio 3D Digital PCR 20K Chip Kit v2. The chip was amplified using the ProFlex $2 \times$ flat PCR system (Thermo Fisher Scientific, Waltham, MA, USA) under the following conditions: $96^{\circ} \mathrm{C}$ for $10 \mathrm{~min}$, followed by 40 amplification cycles $\left(2 \mathrm{~min}\right.$ at $60^{\circ} \mathrm{C}, 30 \mathrm{~s}$ at $\left.98^{\circ} \mathrm{C}\right)$ and $2 \mathrm{~min}$ at $60^{\circ} \mathrm{C}$, followed by a cooling step at $10^{\circ} \mathrm{C}$. After amplification, the chip was read using QuantStudio 3D and analyzed with QuantStudio 3D Analysis Suite cloud software. The results were reported as copies per microliters (copies $/ \mu \mathrm{L}$ ), calculated from the fluorescence signal generated by the amplification of the mutant allele targeted by the FAM dye-labeled probe and the wild-type allele targeted with the VIC dye-labeled probe.

Appendix A.1.4. DNA Methylation Analysis

Samples $\mathrm{S} 1-\mathrm{S} 5$ and $\mathrm{A} 1_{\mathrm{d}}-\mathrm{A} 1_{\mathrm{r}}, \mathrm{A} 2_{\mathrm{d}}-\mathrm{A} 2_{\mathrm{r}}$, and $\mathrm{A} 3_{\mathrm{d}}-\mathrm{A} 3_{\mathrm{r}}$ underwent DNA methylation analysis. The samples were processed in two batches.

The quality- and quantity-checked DNA (500 ng) were treated with bisulfite (EZ96 DNA Methylation-Gold Kit, Zymo Research Corporation, Irvine, CA, USA), and the bisulfite-converted DNA was then hybridized onto the HumanMethylation450 BeadChip (Illumina, San Diego, CA, USA) [45]. The BeadChips were scanned with a HiScan SQ instrument (Illumina, San Diego, CA, USA), and the fluorescence intensities corresponding to the methylation level of each CpG were recorded.

The raw data quality check and methylation Beta ( $\beta$ )-value computation were previously described in [46].

Methylation $\beta$-values with a detection $p$-value $\geq 0.01$ were excluded from the analysis, as well as CpG loci with a detection $p$-value $\geq 0.01$ in more than $20 \%$ of the assayed samples. All the samples had a global call rate higher than $95 \%$.

The CpG sites were annotated to gene regions according to the Infinium HumanMethylation450K Manifest.

Appendix A.1.5. mRNA Expression Analysis

The total RNA of four B-ALL patients at diagnosis $\left(\mathrm{A} 1_{\mathrm{d}}, \mathrm{A} 2_{\mathrm{d}}, \mathrm{A} 3_{\mathrm{d}}\right.$, and $\left.\mathrm{A} 4_{\mathrm{d}}\right)$ and the same four patients at remission $\left(\mathrm{A} 1_{\mathrm{r}}, \mathrm{A} 2_{\mathrm{r}}, \mathrm{A} 3_{\mathrm{r}}\right.$, and $\left.\mathrm{A} 4_{\mathrm{r}}\right)$ were extracted using TRIzol 
reagent (Invitrogen, Thermo Fisher Scientific, Waltham, MA, USA). RNA integrity was assessed using the Fragment Analyzer Automated CE System (Advanced Analytical, Heidelberg, Germany). At least $200 \mathrm{ng}$ of samples with an RNA integrity number $\geq 7$ was processed using the TruSeq RNA Sample Prep V2 (Illumina, San Diego, CA, USA) to prepare cDNA libraries. Whole-transcriptome single-end $(1 \times 75$ cycles) sequencing was performed on the NextSeq500 platform (Illumina, San Diego, CA, USA). Bowtie v2.3.2 [47] was used to align the generated reads to the human genome GRCh38 and to count the number of reads mapped to each gene. The counts of reads that uniquely mapped to annotated genes were performed using the featureCounts program from the Subread package 1.5.3 [48]. The R language package Bioconductor DeSeq2 v1.18.1 was employed to perform differential expression analysis [49]. Only genes with a median of the counts greater than zero in the eight samples (couples $\left.\mathrm{Ai}_{d}-\mathrm{Ai}_{r}, \mathrm{i}=1,2,3,4\right)$ were tested. The expression level of each mRNA was $\log 2$ transformed for the downstream analysis.

\section{References}

1. Steliarova-Foucher, E.; Colombet, M.; Ries, L.A.G.; Moreno, F.; Dolya, A.; Bray, F.; Hesseling, P.; Shin, H.Y.; Stiller, C.A. IICC-3 contributors. International incidence of childhood cancer, 2001-2010: A population-based registry study. Lancet Oncol. 2017, 18, 719-731. [CrossRef]

2. Sanjuan-Pla, A.; Bueno, C.; Prieto, C.; Acha, P.; Stam, R.W.; Marschalek, R.; Menendez, P. Revisiting the biology of infant $\mathrm{t}(4 ; 11) /$ MLL-AF4 ${ }^{+}$B-cell acute lymphoblastic leukemia. Blood 2015, 126, 2676-2685. [CrossRef]

3. Nordlund, J.; Syvanen, A.C. Epigenetics in pediatric acute lymphoblastic leukemia. Semin. Cancer Biol. 2017, 51, 129-138. [CrossRef] [PubMed]

4. Nordlund, J.; Backlin, C.L.; Zachariadis, V.; Cavelier, L.; Dahlberg, J.; Ofverholm, I.; Barbany, G.; Nordgren, A.; Overnas, E.; Abrahamsson, J.; et al. DNA methylation-based subtype prediction for pediatric acute lymphoblastic leukemia. Clin. Epigenetics 2015, 7, 11. [CrossRef] [PubMed]

5. Mill, J.; Heijmans, B.T. From promises to practical strategies in epigenetic epidemiology. Nat. Rev. Genet. 2013, 14, 585-594. [CrossRef]

6. Greaves, M.F.; Maia, A.T.; Wiemels, J.L.; Ford, A.M. Leukemia in twins: Lessons in natural history. Blood 2003, 102, 2321-2333. [CrossRef] [PubMed]

7. Andersson, A.K.; Ma, J.; Wang, J.; Chen, X.; Gedman, A.L.; Dang, J.; Nakitandwe, J.; Holmfeldt, L.; Parker, M.; Easton, J.; et al. The landscape of somatic mutations in infant MLL-rearranged acute lymphoblastic leukemias. Nat. Genet. 2015, 47, 330-337. [CrossRef] [PubMed]

8. Dobbins, S.E.; Sherborne, A.L.; Ma, Y.P.; Bardini, M.; Biondi, A.; Cazzaniga, G.; Lloyd, A.; Chubb, D.; Greaves, M.F.; Houlston, R.S. The silent mutational landscape of infant MLL-AF4 pro-B acute lymphoblastic leukemia. Genes Chromosomes Cancer 2013, 52, 954-960. [CrossRef]

9. Ford, A.M.; Ridge, S.A.; Cabrera, M.E.; Mahmoud, H.; Steel, C.M.; Chan, L.C.; Greaves, M. In utero rearrangements in the trithorax-related oncogene in infant leukaemias. Nature 1993, 363, 358-360. [CrossRef]

10. Gale, K.B.; Ford, A.M.; Repp, R.; Borkhardt, A.; Keller, C.; Eden, O.B.; Greaves, M.F. Backtracking leukemia to birth: Identification of clonotypic gene fusion sequences in neonatal blood spots. Proc. Natl. Acad. Sci. USA 1997, 94, 13950-13954. [CrossRef]

11. Tamai, H.; Miyake, K.; Takatori, M.; Miyake, N.; Yamaguchi, H.; Dan, K.; Shimada, T.; Inokuchi, K. Activated K-Ras protein accelerates human MLL/AF4-induced leukemo-lymphomogenicity in a transgenic mouse model. Leukemia 2011, 25, 888-891. [CrossRef]

12. Trentin, L.; Bresolin, S.; Giarin, E.; Bardini, M.; Serafin, V.; Accordi, B.; Fais, F.; Tenca, C.; De Lorenzo, P.; Valsecchi, M.G.; et al. Deciphering KRAS and NRAS mutated clone dynamics in MLL-AF4 paediatric leukaemia by ultra deep sequencing analysis. Sci. Rep. 2016, 6, 34449. [CrossRef]

13. Zhou, J.D.; Yao, D.M.; Li, X.X.; Zhang, T.J.; Zhang, W.; Ma, J.C.; Guo, H.; Deng, Z.Q.; Lin, J.; Qian, J. KRAS overexpression independent of RAS mutations confers an adverse prognosis in cytogenetically normal acute myeloid leukemia. Oncotarget 2017, 8, 66087-66097. [CrossRef]

14. Perentesis, J.P.; Bhatia, S.; Boyle, E.; Shao, Y.; Shu, X.O.; Steinbuch, M.; Sather, H.N.; Gaynon, P.; Kiffmeyer, W.; Envall-Fox, J.; et al. RAS oncogene mutations and outcome of therapy for childhood acute lymphoblastic leukemia. Leukemia 2004, 18, 685-692. [CrossRef] [PubMed]

15. Driessen, E.M.; van Roon, E.H.; Spijkers-Hagelstein, J.A.; Schneider, P.; de Lorenzo, P.; Valsecchi, M.G.; Pieters, R.; Stam, R.W. Frequencies and prognostic impact of RAS mutations in MLL-rearranged acute lymphoblastic leukemia in infants. Haematologica 2013, 98, 937-944. [CrossRef] [PubMed]

16. Andriano, N.; Iachelli, V.; Bonaccorso, P.; La Rosa, M.; Meyer, C.; Marschalek, R.; Lo Nigro, L. Prenatal origin of KRAS mutation in a child with an acute myelomonocytic leukaemia bearing the KMT2A/MLL-AFDN/MLLT4/AF6 fusion transcript. Br. J. Haematol. 2019, 185, 563-566. [CrossRef] [PubMed] 
17. Gruhn, B.; Taub, J.W.; Ge, Y.; Beck, J.F.; Zell, R.; Hafer, R.; Hermann, F.H.; Debatin, K.M.; Steinbach, D. Prenatal origin of childhood acute lymphoblastic leukemia, association with birth weight and hyperdiploidy. Leukemia 2008, 22, 1692-1697. [CrossRef] [PubMed]

18. Cazzaniga, G.; van Delft, F.W.; Lo Nigro, L.; Ford, A.M.; Score, J.; Iacobucci, I.; Mirabile, E.; Taj, M.; Colman, S.M.; Biondi, A.; et al. Developmental origins and impact of BCR-ABL1 fusion and IKZF1 deletions in monozygotic twins with Ph+ acute lymphoblastic leukemia. Blood 2011, 118, 5559-5564. [CrossRef] [PubMed]

19. Zhu, X.; He, F.; Zeng, H.; Ling, S.; Chen, A.; Wang, Y.; Yan, X.; Wei, W.; Pang, Y.; Cheng, H.; et al. Identification of functional cooperative mutations of SETD2 in human acute leukemia. Nat. Genet. 2014, 46, 287-293. [CrossRef]

20. Chuk, M.K.; McIntyre, E.; Small, D.; Brown, P. Discordance of MLL-rearranged (MLL-R) infant acute lymphoblastic leukemia in monozygotic twins with spontaneous clearance of preleukemic clone in unaffected twin. Blood 2009, 113, 6691-6694. [CrossRef]

21. Maia, A.T.; Koechling, J.; Corbett, R.; Metzler, M.; Wiemels, J.L.; Greaves, M. Protracted postnatal natural histories in childhood leukemia. Genes Chromosomes Cancer 2004, 39, 335-340. [CrossRef]

22. Schmiegelow, K.; Vestergaard, T.; Nielsen, S.M.; Hjalgrim, H. Etiology of common childhood acute lymphoblastic leukemia: The adrenal hypothesis. Leukemia 2008, 22, 2137-2141. [CrossRef] [PubMed]

23. Kuzmichev, A.; Nishioka, K.; Erdjument-Bromage, H.; Tempst, P.; Reinberg, D. Histone methyltransferase activity associated with a human multiprotein complex containing the Enhancer of Zeste protein. Genes Dev. 2002, 16, 2893-2905. [CrossRef]

24. Orlovsky, K.; Kalinkovich, A.; Rozovskaia, T.; Shezen, E.; Itkin, T.; Alder, H.; Ozer, H.G.; Carramusa, L.; Avigdor, A.; Volinia, S.; et al. Down-regulation of homeobox genes MEIS1 and HOXA in MLL-rearranged acute leukemia impairs engraftment and reduces proliferation. Proc. Natl. Acad. Sci. USA 2011, 108, 7956-7961. [CrossRef] [PubMed]

25. Yamazaki, K.; Aso, T.; Ohnishi, Y.; Ohno, M.; Tamura, K.; Shuin, T.; Kitajima, S.; Nakabeppu, Y. Mammalian elongin A is not essential for cell viability but is required for proper cell cycle progression with limited alteration of gene expression. J. Biol. Chem. 2003, 278, 13585-13589. [CrossRef] [PubMed]

26. Beringer, M.; Pisano, P.; Di Carlo, V.; Blanco, E.; Chammas, P.; Vizan, P.; Gutierrez, A.; Aranda, S.; Payer, B.; Wierer, M.; et al. EPOP Functionally Links Elongin and Polycomb in Pluripotent Stem Cells. Mol. Cell 2016, 64, 645-658. [CrossRef]

27. Ohbayashi, N.; Fukuda, M.; Kanaho, Y. Rab32 subfamily small GTPases: Pleiotropic Rabs in endosomal trafficking. J. Biochem. 2017, 162, 65-71. [CrossRef]

28. Chatterton, Z.; Morenos, L.; Mechinaud, F.; Ashley, D.M.; Craig, J.M.; Sexton-Oates, A.; Halemba, M.S.; Parkinson-Bates, M.; Ng, J.; Morrison, D.; et al. Epigenetic deregulation in pediatric acute lymphoblastic leukemia. Epigenetics 2014, 9, 459-467. [CrossRef]

29. Yagi, T.; Morimoto, A.; Eguchi, M.; Hibi, S.; Sako, M.; Ishii, E.; Mizutani, S.; Imashuku, S.; Ohki, M.; Ichikawa, H. Identification of a gene expression signature associated with pediatric AML prognosis. Blood 2003, 102, 1849-1856. [CrossRef]

30. Haouas, H.; Haouas, S.; Uzan, G.; Hafsia, A. Identification of new markers discriminating between myeloid and lymphoid acute leukemia. Hematology 2010, 15, 193-203. [CrossRef] [PubMed]

31. Figueroa, M.E.; Chen, S.C.; Andersson, A.K.; Phillips, L.A.; Li, Y.; Sotzen, J.; Kundu, M.; Downing, J.R.; Melnick, A.; Mullighan, C.G. Integrated genetic and epigenetic analysis of childhood acute lymphoblastic leukemia. J. Clin. Investig. 2013, 123, 3099-3111. [CrossRef] [PubMed]

32. Bohl, S.R.; Claus, R.; Dolnik, A.; Schlenk, R.F.; Döhner, K.; Hackanson, B.; Döhner, H.; Lübbert, M.; Bullinger, L. Decitabine Response Associated Gene Expression Patterns In Acute Myeloid Leukemia (AML). Blood 2013, 122, 3756. [CrossRef]

33. Hansen-Hagge, T.E.; Schafer, M.; Kiyoi, H.; Morris, S.W.; Whitlock, J.A.; Koch, P.; Bohlmann, I.; Mahotka, C.; Bartram, C.R.; Janssen, J.W. Disruption of the RanBP17/Hox11L2 region by recombination with the TCRdelta locus in acute lymphoblastic leukemias with $\mathrm{t}(5 ; 14)(\mathrm{q} 34 ; \mathrm{q} 11)$. Leukemia 2002, 16, 2205-2212. [CrossRef] [PubMed]

34. Gomez, A.M.; Martinez, C.; Gonzalez, M.; Luque, A.; Melen, G.J.; Martinez, J.; Hortelano, S.; Lassaletta, A.; Madero, L.; Ramirez, M. Chemokines and relapses in childhood acute lymphoblastic leukemia: A role in migration and in resistance to antileukemic drugs. Blood Cells Mol. Dis. 2015, 55, 220-227. [CrossRef] [PubMed]

35. Chen, C.; Bartenhagen, C.; Gombert, M.; Okpanyi, V.; Binder, V.; Rottgers, S.; Bradtke, J.; Teigler-Schlegel, A.; Harbott, J.; Ginzel, S.; et al. Next-generation-sequencing of recurrent childhood high hyperdiploid acute lymphoblastic leukemia reveals mutations typically associated with high risk patients. Leuk Res. 2015, 39, 990-1001. [CrossRef]

36. Chen, C.; Bartenhagen, C.; Gombert, M.; Okpanyi, V.; Binder, V.; Teigler-Schlegel, A.; Bradtke, J.; Roettgers, S.; Harbott, J.; Ginzel, S.; et al. Chromothripsis-Mediated Structural Variations and Clonal Evolution In Recurrent Childhood High Hyperdiploid Acute Lymphoblastic Leukemia. Blood 2013, 122, 233. [CrossRef]

37. Feijs, K.L.H.; Cooper, C.D.O.; Zaja, R. The Controversial Roles of ADP-Ribosyl Hydrolases MACROD1, MACROD2 and TARG1 in Carcinogenesis. Cancers 2020, 12, 604. [CrossRef]

38. Sanders, J.E.; Im, H.J.; Hoffmeister, P.A.; Gooley, T.A.; Woolfrey, A.E.; Carpenter, P.A.; Andrews, R.G.; Bryant, E.M.; Appelbaum, F.R. Allogeneic hematopoietic cell transplantation for infants with acute lymphoblastic leukemia. Blood 2005, 105, 3749-3756. [CrossRef]

39. Pui, C.H.; Evans, W.E. Acute lymphoblastic leukemia. N. Engl. J. Med. 1998, 339, 605-615. [CrossRef]

40. Pui, C.H.; Campana, D.; Evans, W.E. Childhood acute lymphoblastic leukaemia-current status and future perspectives. Lancet Oncol. 2001, 2, 597-607. [CrossRef] 
41. Subramanian, A.; Tamayo, P.; Mootha, V.K.; Mukherjee, S.; Ebert, B.L.; Gillette, M.A.; Paulovich, A.; Pomeroy, S.L.; Golub, T.R.; Lander, E.S.; et al. Gene set enrichment analysis: A knowledge-based approach for interpreting genome-wide expression profiles. Proc. Natl. Acad. Sci. USA 2005, 102, 15545-15550. [CrossRef]

42. Cazzaniga, G.; Songia, S.; Biondi, A.; Euro, M.R.D.W.G. PCR Technology to Identify Minimal Residual Disease. Methods Mol. Biol. 2021, 2185, 77-94. [CrossRef]

43. Li, H.; Durbin, R. Fast and accurate long-read alignment with Burrows-Wheeler transform. Bioinformatics 2010, 26, 589-595. [CrossRef]

44. McKenna, A.; Hanna, M.; Banks, E.; Sivachenko, A.; Cibulskis, K.; Kernytsky, A.; Garimella, K.; Altshuler, D.; Gabriel, S.; Daly, M.; et al. The Genome Analysis Toolkit: A MapReduce framework for analyzing next-generation DNA sequencing data. Genome Res. 2010, 20, 1297-1303. [CrossRef]

45. Bibikova, M.; Barnes, B.; Tsan, C.; Ho, V.; Klotzle, B.; Le, J.M.; Delano, D.; Zhang, L.; Schroth, G.P.; Gunderson, K.L.; et al. High density DNA methylation array with single CpG site resolution. Genomics 2011, 98, 288-295. [CrossRef] [PubMed]

46. Guarrera, S.; Viberti, C.; Cugliari, G.; Allione, A.; Casalone, E.; Betti, M.; Ferrante, D.; Aspesi, A.; Casadio, C.; Grosso, F.; et al. Peripheral Blood DNA Methylation as Potential Biomarker of Malignant Pleural Mesothelioma in Asbestos-Exposed Subjects. J. Thorac. Oncol. 2019, 14, 527-539. [CrossRef]

47. Langmead, B.; Trapnell, C.; Pop, M.; Salzberg, S.L. Ultrafast and memory-efficient alignment of short DNA sequences to the human genome. Genome Biol. 2009, 10, R25. [CrossRef] [PubMed]

48. Liao, Y.; Smyth, G.K.; Shi, W. FeatureCounts: An efficient general purpose program for assigning sequence reads to genomic features. Bioinformatics 2014, 30, 923-930. [CrossRef]

49. Love, M.I.; Huber, W.; Anders, S. Moderated estimation of fold change and dispersion for RNA-seq data with DESeq2. Genome Biol. 2014, 15, 550. [CrossRef] [PubMed] 